\title{
Facultative and obligate diapause phenotypes in populations of the European spruce bark beetle Ips typographus
}

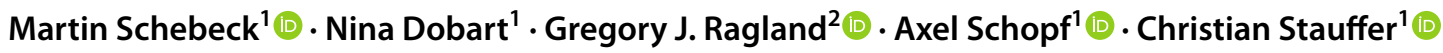

Received: 28 May 2021 / Revised: 20 July 2021 / Accepted: 26 July 2021 / Published online: 5 August 2021

(c) The Author(s) 2021

\begin{abstract}
The bark beetle Ips typographus is the most destructive insect pest in Norway spruce-dominated forests. Its potential to establish multiple generations per year (multivoltinism) is one major trait that makes this beetle a severe pest. Ips typographus enters diapause to adjust its life cycle to seasonally changing environments. Diapause is characterized by developmental and reproductive arrest; it prolongs generation time and thus affects voltinism. In I. typographus a facultative, photoperiodregulated diapause in the adult stage has been described. In addition, the presence of an obligate, photoperiod-independent, diapause has been hypothesized. The diapause phenotype has important implications for I. typographus voltinism, as populations with obligate diapausing individuals would be univoltine. To test for the presence of different I. typographus diapause phenotypes, we exposed Central and Northern European individuals to a set of photoperiodic treatments. We used two ovarian traits (egg number and vitellarium size) that are associated with gonad development, to infer reproductive arrest and thus diapause. We found a distinct effect of photoperiod on ovarian development, with variable responses in Central and Northern European beetles. We observed obligate diapausing (independent of photoperiod) individuals in Northern Europe, and both facultative (photoperiod-regulated) as well as obligate diapausing individuals in Central Europe. Our results show within-species variation for diapause induction, an adaptation to match life cycles with seasonally fluctuating environmental conditions. As the diapause phenotype affects the potential number of generations per season, our data are the basis for assessing the risk of outbreaks of this destructive bark beetle.
\end{abstract}

Keywords Bark beetle $\cdot$ Dormancy $\cdot$ Voltinism $\cdot$ Life cycle regulation $\cdot$ Forest pest $\cdot$ Seasonality

\section{Key Message}

- Diapause, a common strategy to cope with adversity, affects insect seasonality and voltinism.

- Ips typographus expresses a facultative, photoperiodregulated diapause.

Communicated by Andrea Battisti.

Christian Stauffer, Axel Schopf and Gregory J. Ragland have contributed equally.

Martin Schebeck

martin.schebeck@boku.ac.at

1 Department of Forest and Soil Sciences, University of Natural Resources and Life Sciences, Vienna, BOKU, Vienna, Austria

2 Department of Integrative Biology, University of Colorado-Denver, Denver, CO, USA
- In addition, here we describe an obligate, photo-insensitive diapause.

- Facultative and obligate diapause phenotypes show geographic differences in Europe.

- Diapause affects the number of generations/year and is thus important for risk assessment.

\section{Introduction}

Bark beetles are common insects in forest ecosystems (Hulcr et al. 2015; Raffa et al. 2015). The majority of these beetles live in dead and dying plants, and thus have an important ecological function as early decomposers. Some bark beetle species, however, are capable of colonizing healthy or moderately stressed hosts and are therefore important forest pests (Kirkendall et al. 2015). In Europe, Ips typographus (L.) (Coleoptera, Curculionidae, Scolytinae) is the most destructive pest in Norway 
spruce-dominated forests (Kausrud et al. 2012; Schelhaas et al. 2003; Wermelinger 2004). It shows extensive population outbreaks, which are usually triggered by abiotic disturbance events, e.g. storm, snowfall or drought, providing high amounts of suitable breeding material. This usually results in a rapid increase of beetle population densities, followed by severe Norway spruce mortality (Marini et al. 2017; Seidl et al. 2016; Stadelmann et al. 2014; Wermelinger 2004).

In addition, several intrinsic, species-specific traits account for the potential of I. typographus to efficiently colonize and kill host trees. For example, it has a high fecundity (Anderbrant 1990; Anderbrant and Löfqvist 1988), an efficient intraspecific chemical communication (Schlyter et al. 1987a; Schlyter et al. 1987b), associations with blue-stain fungi (Horntvedt et al. 1983; Lieutier et al. 2009) and it can establish multiple generations per year (Wermelinger 2004; Wermelinger et al. 2012). Ips typographus voltinism strongly varies across its geographic range. For instance, in Central Europe and low elevation habitats it usually produces two, sometimes three, generations per year (Baier et al. 2007; Wermelinger et al. 2012). In Northern Europe and high elevation sites only one generation is often established (Jönsson et al. 2009; Wermelinger 2004). Major parts of the beetle's life history, like developmental rate or reproduction, are driven by ambient temperature (Wermelinger and Seifert 1998; Wermelinger and Seifert 1999). In addition, photoperiod is another important factor regulating the I. typographus life cycle, as it influences the induction of a reproductive diapause (Dolezal and Sehnal 2007; Schebeck et al. 2017; Schopf 1985; Schopf 1989; Schroeder and Dalin 2017).

Diapause is a common phenotype in insects that is induced during unfavourable seasons (Tauber and Tauber 1976; Tauber et al. 1986). It is characterized by a suppression of morphological development and reproduction, that is often accompanied by suppressed metabolic rate and enhanced resistance to external stressors (Denlinger 2002; Hahn and Denlinger 2011; Kostal 2006). In addition to an increased chance of survival during adverse periods, diapause prolongs generation time and thus affects phenology and voltinism (Danks 1987; Visser et al. 2010). Therefore, understanding the physiology and environmental sensitivity of diapause is not only important to understand seasonality and life cycle regulation of insects, it has also important implications for pest management as it influences the potential number of generations per year. Diapause is often not a fixed, or obligate element of a species' life cycle; instead, induction of diapause is often mediated by environmental signals, e.g. photoperiod or thermoperiod (Denlinger 2002; Kostal 2006). Widely distributed species often exhibit marked clines in photoperiod-sensitivity of diapause induction or termination that translate into voltinism clines
(Bradshaw et al. 2003; Paolucci et al. 2013; Tauber and Tauber 1972; Winterhalter and Mousseau 2007).

Ips typographus enters a reproductive diapause in the adult stage with photoperiod as main regulator (i.e. facultative, or environmentally inducible) (Dolezal and Sehnal 2007; Schebeck et al. 2017; Schopf 1985; Schopf 1989; Schroeder and Dalin 2017). Diapause induction is driven by short day lengths (Dolezal and Sehnal 2007; Schopf 1989; Schroeder and Dalin 2017), but high temperatures can override the photoperiodic effect and delay the onset of diapause (Dolezal and Sehnal 2007). The critical day length to induce diapause (i.e. day length at which $50 \%$ of a population entered diapause) varies across the species' European range, to adjust reproduction, development and stress resistance to local conditions. The photoperiodic cue is generally perceived in late summer/early fall (Dolezal and Sehnal 2007; Schopf 1989; Schroeder and Dalin 2017). Diapause is terminated by low temperatures in mid-winter and followed by a post-diapause quiescence until favourable conditions prevail the following spring (Dolezal and Sehnal 2007).

In most populations, the timing of diapause induction affects the voltinism of I. typographus. The beetles continue to develop in successive generations until individuals perceive the photoperiodic cue for diapause induction (Annila 1969; Dolezal and Sehnal 2007; Schopf 1985; Schopf 1989; Schroeder and Dalin 2017). Previous findings, however, reported that certain European populations established only one generation per year, although conditions, i.e. temperature and day length, would be favourable to continue reproduction and morphogenesis (Annila 1969; Dworschak 2013; Netherer 2003). In addition, some portion of individuals within Northern European populations were in diapause, even when they were exposed to extreme long day lengths (Dolezal and Sehnal 2007; Schroeder and Dalin 2017). Therefore, some authors hypothesized that some populations of I. typographus might enter diapause independent of a photoperiodic induction, and thus have an obligate diapause phenotype (Schebeck et al. 2017; Schroeder and Dalin 2017). However, robust quantitative evidence for obligate diapause has not been documented previously.

Here, we test for differences in the photoperiodic sensitivity of diapause induction and for the presence of an obligate diapause among Central and Northern European populations of I. typographus. We exposed beetles to different photoperiods under laboratory conditions and used two traits associated with gonad development, egg numbers and ovary size, to assess whether females entered reproductive arrest, and thus diapause. We hypothesize that an obligate diapause phenotype would rather be found in Northern Europe and result in univoltine populations, an adaptation to environments with short favourable seasons. These observations would have important implications to understand outbreak patterns of the most destructive pest of European 
spruce forests and unravel a long-standing question about $I$. typographus life history.

\section{Materials and methods}

\section{Insect collection}

To study the occurrence of I. typographus diapause phenotypes in different habitats, individuals from three geographic locations were sampled: one Central European, low elevation site (LOW; Prinzersdorf, Austria; $48^{\circ} 22^{\prime} \mathrm{N}$, $15^{\circ} 48^{\prime} \mathrm{E}$; $350 \mathrm{~m}$ a.s.l.), one Central European, high elevation location (HIGH; Gesäuse, Austria; $47^{\circ} 35^{\prime} \mathrm{N}, 14^{\circ} 38^{\prime} \mathrm{E}$; $1500 \mathrm{~m}$ a.s.l.) and one Northern European, Scandinavian site (NORTH; Vindeln, Sweden; $64^{\circ} 12^{\prime} \mathrm{N}, 19^{\circ} 43^{\prime} \mathrm{E} ; 300 \mathrm{~m}$ a.s.1.). Beetles of the overwintered, i.e. parental, generation were randomly collected from freshly colonized Norway spruce. This allowed us to study diapause expression with reproductively active I. typographus, all of the same phenological state. Live beetles were placed on spruce phloem and transferred to the laboratory for experimental trials.

\section{Experimental setup}

A standard procedure to evaluate diapause expression (i.e. whether or not diapause has been induced) in I. typographus was applied (Dolezal and Sehnal 2007; Schroeder and Dalin 2017). One-hundred unsexed adults were put in insect cages with one log of Norway spruce $(\sim 60 \mathrm{~cm}$ length, $\sim 25 \mathrm{~cm}$ diameter), with two independent logs per experimental trial. To initiate colonization of the log and brood establishment, beetles were first exposed to $25{ }^{\circ} \mathrm{C}$ and a photoperiod of $16 \mathrm{~h}$ light : $8 \mathrm{~h}$ dark for ten days. After males colonized a log and excavated a mating chamber, females joined them, mated and laid eggs. To test for the presence of an obligate diapause phenotype, diapause expression of this offspring generation developing in the laboratory (i.e. the first generation) under different conditions was evaluated.

On day $11, \log$ s were transferred to various photoperiodic conditions. To assess diapause expression of $I$. typographus from LOW, HIGH and NORTH at different day lengths, three photoperiodic treatments were applied: Beetles from all three locations were exposed to long-day (LD, light (1) : dark (d) 16:8 h) and short-day (SD, $1: \mathrm{d}$ $8: 16 \mathrm{~h}$ ) conditions. In addition, extra-long-day (ELD, $1: \mathrm{d}$ 23:1 h) conditions were applied with NORTH individuals, to assess their response to longer day lengths in their natural habitat (maximum sunlight during summer $\sim 21 \mathrm{~h}$, plus civil twilight; www.shmi.se). Experiments were performed in incubators at constant temperatures of $20^{\circ} \mathrm{C}$, as the effect of photoperiod on diapause induction is overridden at temperatures above $23{ }^{\circ} \mathrm{C}$ (Dolezal and Sehnal 2007). All experimental trials were terminated after 80 days, as the development of one generation (from the egg to the end of the maturation feeding of young adults) at $20{ }^{\circ} \mathrm{C}$ lasts on average $\sim 75$ days (Wermelinger and Seifert 1998). Diapause expression of I. typographus was evaluated after individuals finished their development and left logs, or after the end of experiments when beetles remained in the bark (details see below).

\section{Measurements to evaluate diapause expression}

We measured two characteristics of ovarian development to assess whether females were reproductively active or if they had entered reproductive arrest. The former phenotype suggests non-diapause development, while the latter suggests diapause induction. First, we counted the total number of eggs in the vitellarium (basal part of the ovariole) for each of the four ovarioles (Merker and Wild 1954), then calculated the mean number of eggs per ovariole per female. Second, we calculated the mean relative length of the vitellarium (vitellarium length $[\mathrm{mm}]$ : total ovariole length $[\mathrm{mm}]$ ) for each of the four ovarioles for each female. Measurements of ovary size were performed with IC Measure (www.theim agingsource.de).

To infer effects of diapause expression on the life history of I. typographus, we also accounted for the emergence behaviour of young adults developing at SD, LD and ELD treatments. Generally, non-diapausing young adults emerge to establish a new generation, whereas diapausing beetles prepare for hibernation (either in the bark, i.e. no emergence, or in the litter, i.e. emergence) (Annila 1969). Thus, the two ovary traits of emerged and non-emerged females were evaluated, to assess their reproductive/diapause status. During the main phase of emergence from logs, about 25 females per experimental condition were collected daily and dissected. Likewise, on average 25 non-emerged females were randomly selected from their breeding systems (with only one individual per system) by de-barking the logs after the end of experiments and dissected as above (overview on sample sizes see Supplementary Information 1).

Distinguishing diapausing from non-diapausing females requires that we clearly define the ovarian development phenotypes (see above) for beetles known to be not in diapause. We thus established control cohorts of beetles in which diapause was induced and then terminated under conditions known to produce reproductively active, post-diapause females (Dolezal and Sehnal 2007). After beetles from all locations were exposed to SD and $20^{\circ} \mathrm{C}$ for 80 days (individuals entered diapause), logs were exposed to chilling 
conditions at $5{ }^{\circ} \mathrm{C}$ for 90 days at $\mathrm{SD}$ (to terminate diapause), and then to LD and $20{ }^{\circ} \mathrm{C}$ (modified after (Dolezal and Sehnal 2007)). Subsequently, about 25 emerged females during peak emergence from logs per location were dissected and measured for the same two ovary traits described above.

\section{Data analyses}

To assess whether I. typographus from LOW, HIGH and NORTH, developing under different photoperiodic conditions, form distinct clusters, the mean number of eggs per ovariole and the mean relative vitellarium length were visualized in a biplot. Subsequently, for each of the three locations the two ovarian traits of emerged and non-emerged females, developing at SD, LD and ELD, were compared to distinguish diapausing from non-diapausing individuals, with data of post-diapause females as control group for nondiapause development.

Before comparing the two ovarian traits among these groups, normal distribution of data was evaluated using a Shapiro-Wilk normality test. Normally distributed datasets were further analysed using an ANOVA. In case of variance homogeneity-evaluated by a Levene test in the R package car (Fox and Weisberg 2019)—ovarian traits among groups were subsequently compared applying Tukey's HSD post hoc test. If the Levene test showed significant results $(p<0.05)$ a Welch test, with Games-Howell post hoc tests (R package userfriendlyscience (Peters 2018)), was applied. Non-normally distributed datasets were analysed using a Kruskal-Wallis test, with a Dunn test (with adjusted p-values applying the Benjamini-Hochberg method) as post hoc tests. All analyses were performed in R, version 4.0.2 (RCoreTeam 2020), and results were visualized using the packages ggplot2 (Wickham 2016) and ggthemes (Arnold et al. 2021). Raw data of egg numbers and vitellarium size are provided in Supplementary Information 4.

\section{Results}

\section{Beetles from Northern Europe suppressed ovarian development regardless of photoperiodic condition}

Visualizing the mean number of eggs per ovariole and the mean relative vitellarium length in a biplot revealed that NORTH females clearly clustered by experimental treatment. Post-diapause females were separated from emerged and non-emerged females developing at SD, LD and ELD. The 90th percentile around the centroids of the bivariate distributions for the two ovarian traits for post-diapause females did not overlap with the 90th percentile of beetles developing at all other experimental treatments, which showed strong overlaps among each other (Fig. 1a).
The mean number of eggs of post-diapause females was significantly higher than of individuals exposed to all other conditions ( $p<0.001$, Kruskal-Wallis test, Dunn post hoc test), which suggests suppression of ovarian development at SD, LD and ELD, although a few outliers are observed (Figs. 1, 2). Emerged NORTH females developing at both LD and ELD conditions had low mean egg numbers (2.52 and 2.26 eggs/ovariole, respectively) which did not differ significantly ( $p=0.552$, Kruskal-Wallis test, Dunn post hoc test). Non-emerged females under LD and ELD had similar mean egg numbers (2.70 and 2.01 eggs/ovariole, respectively), which differed significantly ( $p=0.021$, Kruskal-Wallis test, Dunn post hoc test). Under SD conditions mean egg numbers were in the same range and not significantly different among each other (emerged females: 2.16 eggs/ovariole, non-emerged females: 2.43 eggs/ovariole; $p=0.226$, Kruskal-Wallis test, Dunn post hoc test; Supplementary Information 1, further details on significant differences are provided in Supplementary Information 2 and Supplementary Information 3).

The mean relative vitellarium length of post-diapause individuals was also significantly longer as compared to the individuals that developed at all other treatments ( $p<$ 0.003, Kruskal-Wallis test, Dunn post hoc test). Individuals that developed at LD and ELD and emerged from logs had a similar relative vitellarium length, which did not differ significantly from each other $(p=0.335$, Kruskal-Wallis test, Dunn post hoc test, Fig. 3). Both non-emerged females at LD and ELD had similar average relative vitellarium lengths ( $p=0.001$, Kruskal-Wallis test, Dunn post hoc test, Fig. 3). The mean relative vitellarium length of emerged and non-emerged individuals exposed to SD conditions was in the same range, with no significant differences $(p=0.328$, Kruskal-Wallis test, Dunn post hoc test). Further, details on mean values and significant differences are provided in Supplementary Information 1, Supplementary Information 2 and Supplementary Information 3.

\section{Non-emerged beetles from Central Europe suppressed ovarian development at short days}

Females from the two Central European locations that developed under SD conditions and did not emerge from logs showed similar mean egg numbers per ovariole (LOW: 2.95, HIGH: $3.58 ; p=0.023$, Kruskal-Wallis test, Dunn post hoc test, Fig. 2). The mean relative vitellarium length of these females was 0.39 in LOW and 0.41 in HIGH, which did not differ significantly from each other $(p=0.246$, ANOVA, Fig. 3). These results on egg numbers and vitellarium size indicate a suppression of ovarian development in nonemerged SD beetles, as they were significantly different from Central European post-diapause females and emerged LD 
Fig. 1 Grouping of emerged and non-emerged Ips typographus females by mean egg numbers and relative vitellarium length, developing at different photoperiodic conditions. ELD $=$ extra-long-day $(1: \mathrm{d} 23 \mathrm{~h}$ :

$1 \mathrm{~h}) ; \mathrm{LD}=$ long-day $(1: \mathrm{d} 16 \mathrm{~h}$ : $8 \mathrm{~h}) ; \mathrm{SD}=$ short-day $(1: \mathrm{d} 8 \mathrm{~h}$ : $16 \mathrm{~h}$ ); post-diapause $=$ development at diapause inducing and termination conditions, with subsequent transfer to favourable conditions. Solid line $=$ 50th percentile of distribution of data. Dashed line $=90$ th percentile of distribution of data. a NORTH $=$ Northern Europe, Scandinavia. $\mathbf{b}$ LOW = Central Europe, low elevation. c $\mathrm{HIGH}=$ Central Europe, high elevation

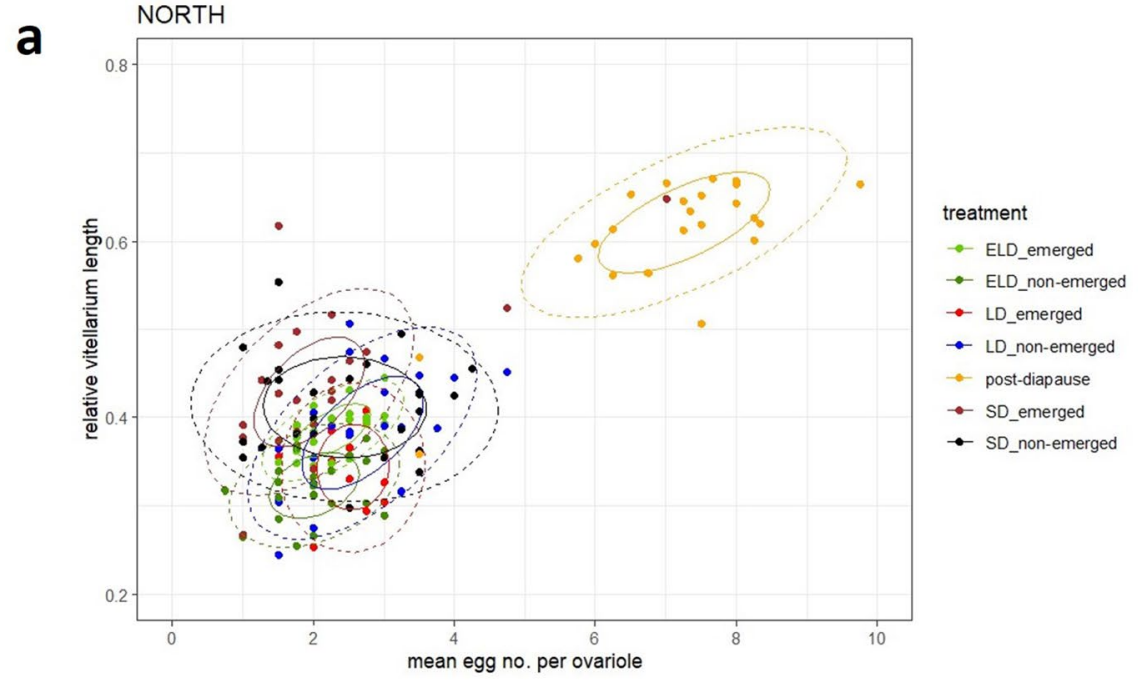

b

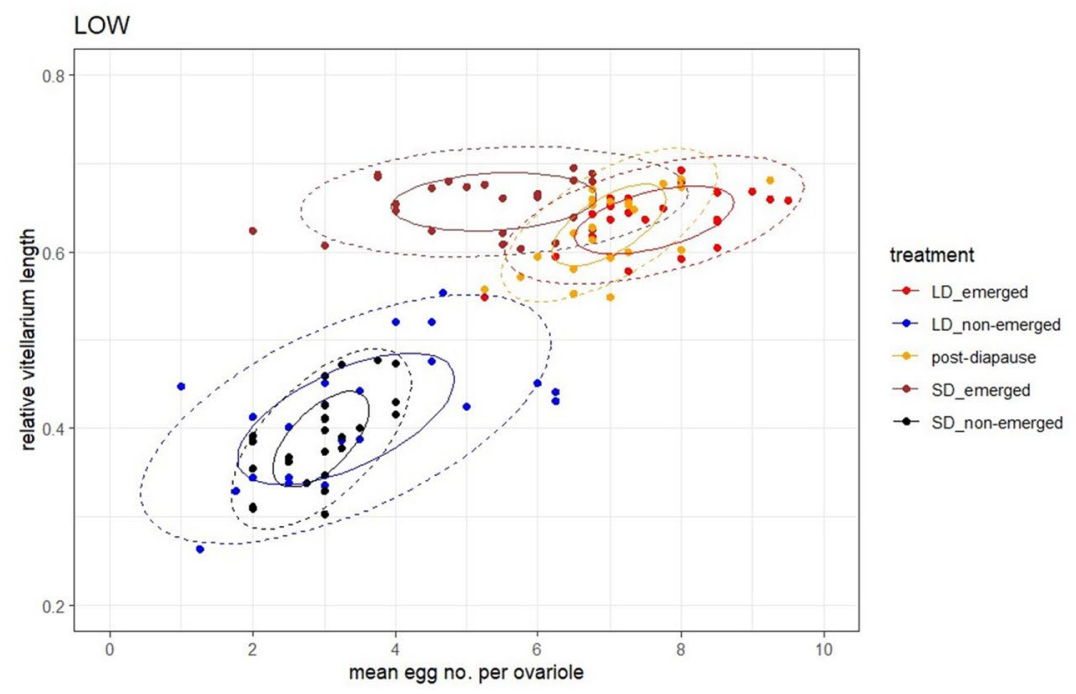

C

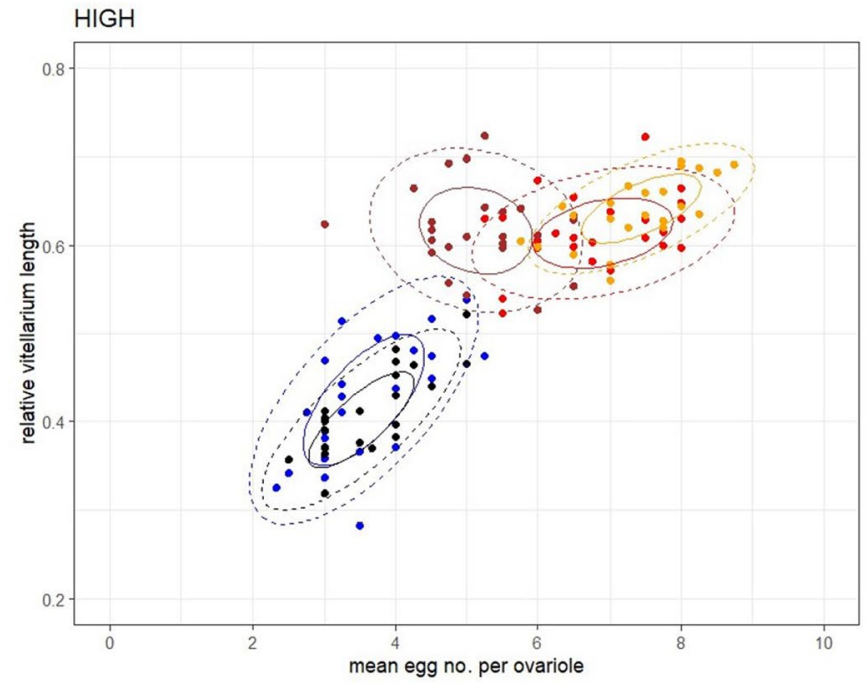

treatment

$\rightarrow$ LD_emerged

$\rightarrow$ LD_non-emerged

- post-diapause

- SD_emerged

- SD_non-emerged 

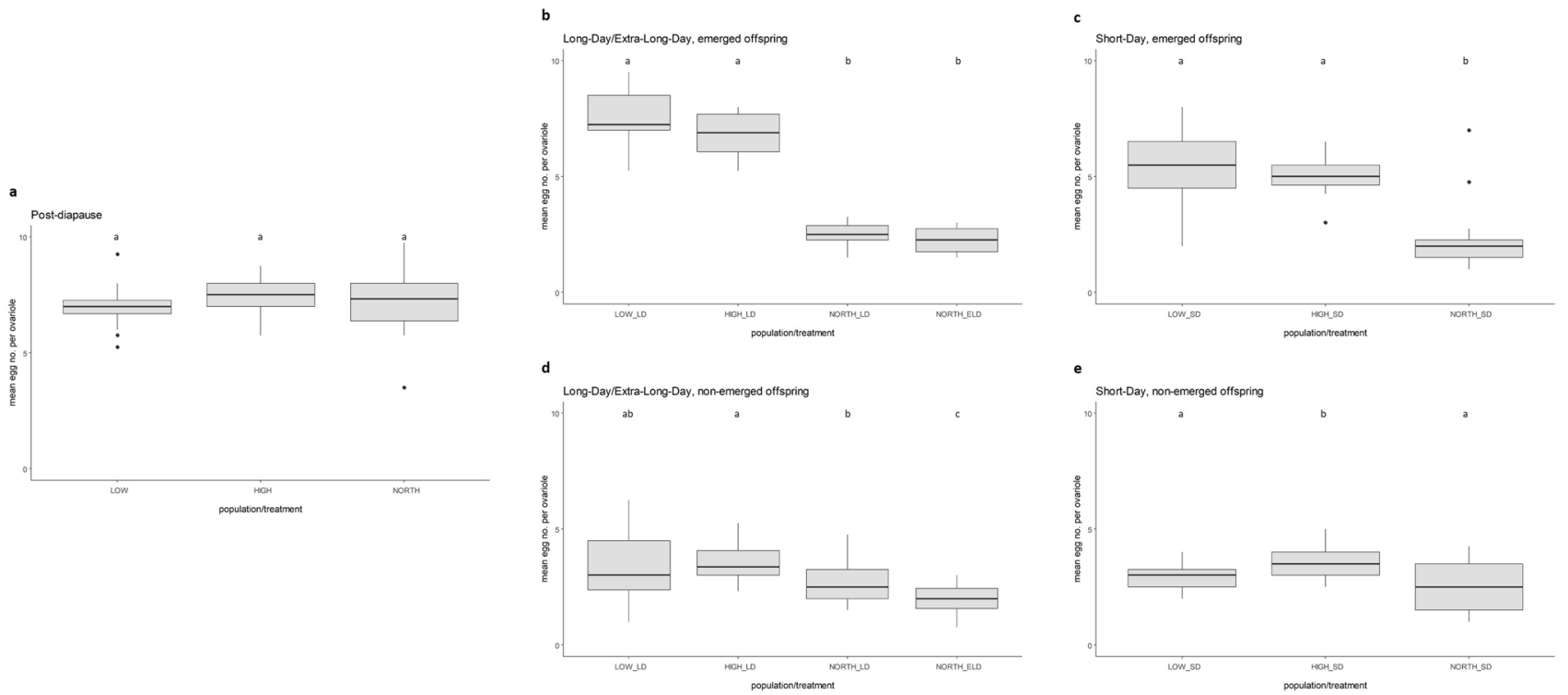

Fig. 2 Mean number of eggs per ovariole in Ips typographus females developing at different experimental conditions. LOW $=$ Central Europe, low elevation; HIGH = Central Europe, high elevation; NORTH $=$ Northern Europe, Scandinavia. ELD = extra-long-day $(1$ : d $23 \mathrm{~h}: 1 \mathrm{~h})$; LD = long-day $(1: \mathrm{d} 16 \mathrm{~h}: 8 \mathrm{~h})$; SD = short-day
(1 : $\mathrm{d} 8 \mathrm{~h}: 16 \mathrm{~h}$ ). a Post-diapause females from LOW, HIGH and NORTH. b Emerged females at LD and ELD. c Emerged females at SD. d Non-emerged females at LD and ELD. e Non-emerged females at SD. Different lower case letters indicate significant differences $(p$ $<0.05)$
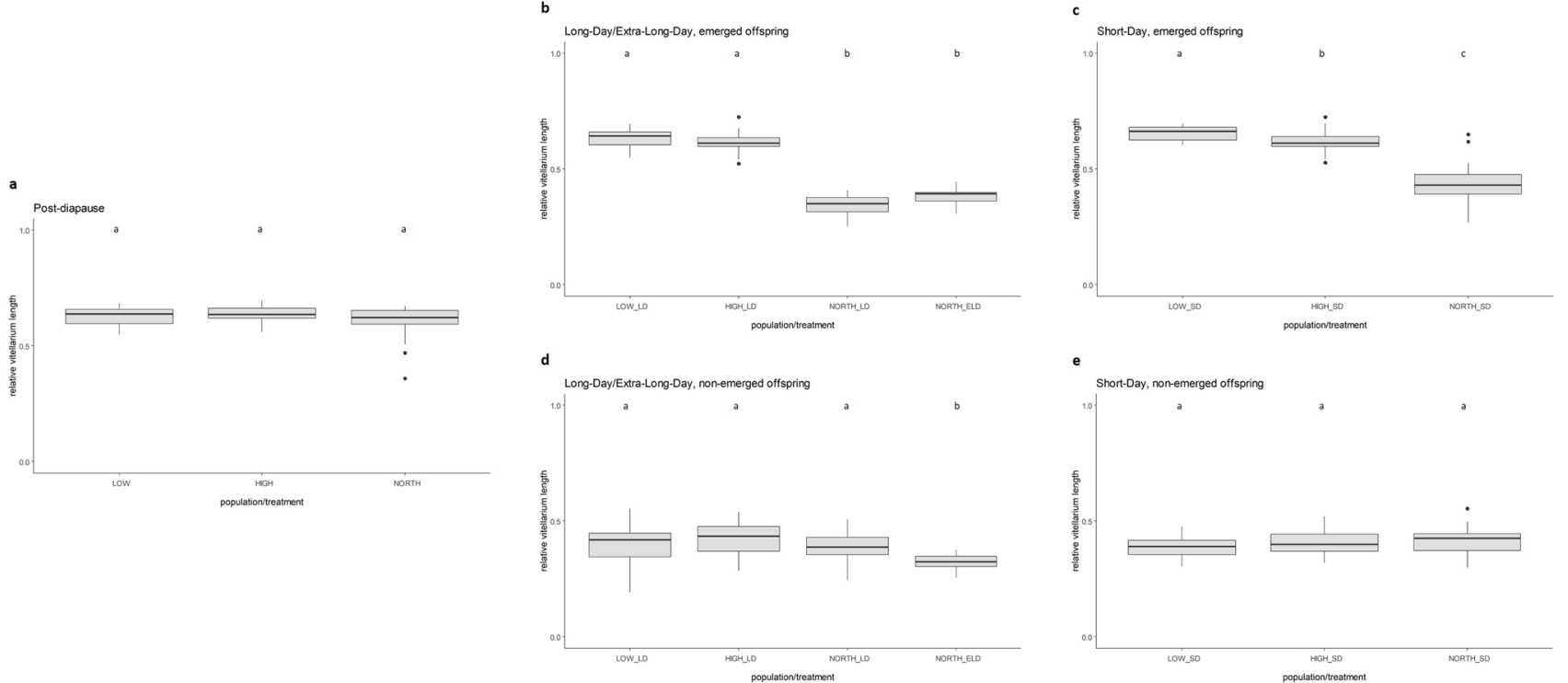

Fig. 3 Mean relative vitellarium length of Ips typographus females developing at different experimental conditions. LOW $=$ Central Europe, low elevation; HIGH = Central Europe, high elevation; NORTH $=$ Northern Europe, Scandinavia. ELD = extra-long-day $(1$ : d $23 \mathrm{~h}: 1 \mathrm{~h}) ; \mathrm{LD}=$ long-day $(1: \mathrm{d} 16 \mathrm{~h}: 8 \mathrm{~h}) ; \mathrm{SD}=$ short-day

individuals ( $p<0.001$, Kruskal-Wallis test, Dunn post hoc test; details see Supplementary Information 3).

This was supported by the biplot results of LOW and HIGH where non-emerged SD females were clearly
(1 : d $8 \mathrm{~h}: 16 \mathrm{~h})$. a Post-diapause females from LOW, HIGH and NORTH. b Emerged females at LD and ELD. c Emerged females at SD. d Non-emerged females at LD and ELD. e Non-emerged females at SD. Different lower case letters indicate significant differences ( $p$ $<0.05)$

separated from reproductively active, post-diapause females, as the 90th percentile around the centroids of those groups in both populations did not overlap (Fig. 1b, c). Similarly, the relative vitellarium length of post-diapause females from both populations was significantly 
longer as compared to non-emerged SD individuals $(p<$ 0.001, Kruskal-Wallis test, Dunn post hoc test; details see Supplementary Information 3).

\section{Beetles from Central Europe showed a variable response to long-day conditions}

Emerged LD females from LOW had mean egg numbers of 7.61, emerged LD individuals from HIGH had a mean value of 6.85 eggs per ovariole, which did not differ significantly ( $p=0.180$, Kruskal-Wallis test, Dunn post hoc test, Fig. $2 b)$. These numbers were in the same range compared to post-diapause females from the respective population, with no significant differences (LOW: $p=0.368$, HIGH: $p=$ 0.369, Kruskal-Wallis test, Dunn post hoc test, Fig. 2), suggesting no suppression of ovarian development in emerged LD females.

The relative vitellarium lengths of emerged individuals at LD from LOW and HIGH were in the same range and not significantly different $(p=0.297$, Kruskal-Wallis test, Dunn post hoc test, Fig. 3). They had similar values as compared to post-diapause females from the respective population, also showing no significant differences (LOW: $p=0.906$, HIGH: $p=0.297$, Kruskal-Wallis test, Dunn post hoc test). These findings were supported by our biplot analysis where postdiapause females and emerged LD females in both LOW and HIGH showed strong overlaps among each other (Fig. 1 $b, c)$.

A different pattern of ovarian development was found in LD females that did not emerge from logs. In LOW and HIGH on average 3.33 and 3.60 eggs per ovariole, respectively, were observed, which did not differ significantly ( $p$ $=0.132$, Kruskal-Wallis test, Dunn post hoc test, Fig. 2). Similarly, the relative vitellarium length of these females did not show significant differences ( $p=0.816$, Kruskal-Wallis test, Dunn post hoc test, Fig. 3). Moreover, these females formed clusters with non-emerged SD individuals in the biplot analysis (Fig. 1b, c), suggesting a suppression of ovarian development when females remained in logs, even under LD photoperiods.

\section{Central European beetles can develop reproductively active ovaries under short-day conditions}

We also observed Central European beetles that were exposed to SD conditions and emerged from logs. Females from LOW and HIGH had an average of about five eggs per ovariole, showing no significant differences among each other $(p=0.604$, Kruskal-Wallis test, Dunn post hoc test, Fig. 2). The average relative vitellarium length of LOW females was 0.65 and that of HIGH individuals was 0.62, which differed significantly ( $p=0.044$, Kruskal-Wallis test,
Dunn post hoc test, Fig. 3). The mean egg numbers of these females showed intermediate values between reproductively active, post-diapause individuals (and emerged LD individuals from Central Europe) and non-emerged SD females with suppressed ovary development (Fig. 2). However, the data on the relative vitellarium lengths were in the same range as in reproductively active individuals (Fig. 3, Supplementary Information 1; details on significant differences are provided in Supplementary Information 2 and Supplementary Information 3). Moreover, the biplot of the population LOW showed that the 90th percentile around the centroids of emerged LD and SD as well as post-diapause individuals were overlapping among each other, but were separated from the group consisting of non-emerged LD and non-emerged SD females (Fig. 1b). A similar pattern was observed in the biplot of the population HIGH, although a slight overlap among non-emerged LD and emerged SD females occurred (Fig. 1c).

\section{Discussion}

\section{Gonad development and diapause in European $I$. typographus}

The use of two ovarian traits, egg numbers and vitellarium size, helped to evaluate the reproductive status of I. typographus females and to infer whether diapause was induced or not. Data of post-diapause beetles provided information on reproductively active (= non-diapausing) individuals, which were subsequently used as control groups for comparisons with females developing at various photoperiodic treatments. Interestingly, results of egg numbers and vitellarium size of post-diapause females showed similar values across all locations, suggesting a comparable reproductive potential in individuals from different origin.

In Northern European I. typographus ovarian development of first-generation beetles was suppressed regardless of photoperiodic treatment, although a small number of outliers was observed. Females exposed to SD, LD and even ELD (either emerged or non-emerged) had fewer eggs in their ovarioles and shorter vitellarium lengths as compared to post-diapause individuals. This was corroborated by their clustering in the biplot analysis where post-diapause females were clearly separated from individuals developing at all other photoperiods. Moreover, values of the two ovary traits of Northern females from SD, LD and ELD treatments were in the same range as compared to Central European individuals with suppressed gonad development, e.g. non-emerged SD females. This indicates that first-generation females from Northern Europe entered diapause even under favourable environmental conditions, i.e. extreme long photoperiods. Comparing these results with the ovary development of 
NORTH post-diapause females shows that first-generation beetles from this population have to experience a chilling period, i.e. winter conditions in the field, to terminate diapause before becoming reproductively active, which suggests the expression of an obligate diapause. The existence of this phenotype has been hypothesized (Schebeck et al. 2017; Schroeder and Dalin 2017). Our detailed data on ovary development provide evidence for this hypothesis, a longstanding question in I. typographus life history.

Schroeder and Dalin (2017) described a critical day length of $\sim 19$ hours and a diapause incidence of about $20 \%$ at a day length of 23.5 hours for I. typographus from Northern Sweden (i.e. the same region as our NORTH population). Dolezal and Sehnal (2007), however, described a diapause incidence of $100 \%$ when exposing beetles from Southern Sweden to photoperiodic conditions of $18: 6 \mathrm{~h}$. Our results on egg numbers and vitellarium size clearly show that nearly all NORTH individuals were in diapause at all photoperiodic conditions, which illustrate a high incidence of obligate diapausing individuals in Northern Europe.

Similarly, ovary development was suppressed in Central European females that developed under SD photoperiods and remained in their breeding systems. Both egg numbers and vitellarium lengths were on average significantly smaller as compared to post-diapause females and emerged LD individuals, clearly indicating that individuals had entered diapause. These results support previous findings on diapause induction by short day length (Dolezal and Sehnal 2007; Schopf 1989).

In contrast, Central European beetles from LOW and HIGH that developed under LD and emerged from logs showed no suppression of gonad development, and thus no diapause expression. The values of the two ovarian traits were in the same range as in post-diapause individuals, corroborated by forming distinct clusters in the biplot analyses. This is in line with previous work where a critical day length for diapause induction of Central European I. typographus of $<15$ hours was described (Dolezal and Sehnal 2007; Schopf 1989), indicating a facultative diapause phenotype.

Interestingly, we also found females that were exposed to $L D$ and remained in their breeding systems. These individuals showed ovarian traits that reflect a suppression of gonad development and therefore diapause expression, even under favourable photoperiodic conditions, suggesting the presence of obligate diapause phenotypes also in lower latitudes. These findings suggest genetic polymorphism in Central European I. typographus with different responses to diapause-inducing, photoperiodic cues. Our results might explain previous field observations where I. typographus was reproductively inactive although permissive temperature and photoperiodic conditions prevailed (Dworschak 2013; Netherer 2003).
Although developing at photoperiodic conditions below the critical day length, emerging I. typographus under SD conditions from Central European sites showed also ovarian traits reflecting no suppression of gonad development, i.e. no diapause. Despite having fewer eggs in their ovarioles than emerged LD females and post-diapause females, their vitellarium length showed values similar to non-diapausing and post-diapause beetles. Moreover, these emerged SD individuals clustered with post-diapause and emerged LD females in the biplot. These results suggest genetic polymorphism towards photoperiodic cues within populations, however, with lower egg numbers under short day lengths.

Taken together, we found clear differences in diapause expression and photoperiodic response in European $I$. typographus among geographically distinct populations. The presence of two diapause phenotypes, i.e. facultative and obligate, within this bark beetle species has been hypothesized previously (Schebeck et al. 2017; Schroeder and Dalin 2017). Our data show that I. typographus expresses a facultative (photoperiod-regulated) diapause, corroborating previous findings (Dolezal and Sehnal 2007; Schopf 1989; Schroeder and Dalin 2017). Moreover, we found Central and Northern European individuals expressing diapause, even at suitable photoperiodic conditions, i.e. LD and ELD. Therefore, we propose that I. typographus does not only enter a facultative, photoperiod-mediated diapause. It also expresses an obligate diapause in both Central and Northern European populations, where individuals became insensitive to photoperiodic cues that are experienced under natural conditions. Future studies should focus on diapause expression of $I$. typographus from different origin, to increase our knowledge on the occurrence and geographic distribution of facultative and obligate diapause phenotypes in European populations.

\section{Ips typographus diapause and its effects on seasonality and voltinism}

The presence of two diapause phenotypes, i.e. facultative and obligate, has major implications for the phenology and voltinism of I. typographus. Populations with facultative diapausing individuals can produce new offspring generations until diapause is induced by short-day photoperiods in late summer/early fall (Dolezal and Sehnal 2007; Schopf 1989; Schroeder and Dalin 2017). Therefore, populations with facultative diapausing individuals have the potential to establish multiple generations per year, i.e. multivoltinism, assumed suitable temperature conditions prevail (Baier et al. 2007; Jakoby et al. 2019; Jönsson et al. 2009; Wermelinger et al. 2012). Populations with obligate diapausing I. typographus, however, can produce only one generation per year (univoltinism) as individuals enter reproductive and developmental arrest as part of their life cycle. In these univoltine populations diapause has to be terminated by low winter 
temperatures (Dolezal and Sehnal 2007) to resume reproduction and morphogenesis the following spring.

A few individuals in the Northern European population, however, had higher egg numbers similar to Central European females (e.g. outliers in Figs. 1, 2). They seem to have some capacity to develop successive generations in one season, reflecting a certain potential for bivoltinism in this region of the species' range.

Expressing an obligate diapause can result in a tradeoff. The reproductive outcome of I. typographus might be smaller when only one generation per year is produced, however, individuals that refrain from establishing a second generation can increase their overwinter survival. The favourable season in higher latitudes is generally shorter than in the South and I. typographus leaves its breeding system to search for a suitable overwintering site already in summer or stays in the bark to prepare for hibernation (Annila 1969; Schebeck et al. 2017). Ips typographus survives harsh winters only as an adult (Stefkova et al. 2017). Thus, beetles that express an obligate diapause refrain from producing a second generation that might not reach the adult stage before the onset of the cold season, resulting in a high risk of preimaginal overwintering mortality. Instead I. typographus likely invests resources for physiological and behavioural preparations (Kostal et al. 2011; Kostal et al. 2007) for a safe overwintering of adults and resumes reproduction the following year.

In upcoming research, diapause development of $I$. typographus should be studied from numerous populations across its entire range. This would provide important data on the occurrence of obligate and facultative diapausing individuals, and inform us about ratios of both diapause phenotypes along latitudinal and altitudinal clines. This information can subsequently be implemented in phenology models (Baier et al. 2007; Jakoby et al. 2019; Jönsson et al. 2009) to estimate voltinism patterns across populations in fine resolution. Finally, combinations of various environmental factors (photoperiod, temperature, phloem quality) can contribute to a complex regulation of reproductive diapause in I. typographus. These combinations should be in focus of future research to get a comprehensive understanding of this developmental pathway.

\section{Authors' contribution}

M.S., N.D., A.S. and C.S. designed experiments. M.S. and N.D. performed experiments. M.S., N.D. and G.J.R. analysed data. All authors contributed in writing and revising the manuscript.
Supplementary Information The online version contains supplementary material available at https://doi.org/10.1007/s10340-021-01416-w.

Acknowledgements We thank David L. Denlinger (OSU, Columbus, $\mathrm{OH}$ ) and Daniel A. Hahn (UF, Gainesville, FL) for stimulating discussions on diapause. Furthermore, we thank Martin L. Schroeder, Simon Karvemö and Ake Lindelöw (LSU, Uppsala, Sweden) and Vid Bakovic (Biology Centre CAS, České Budějovice) for supporting Ips typographus collections, and the forest owners in Prinzersdorf and Gesäuse (particularly Felix Montecuccoli and Alexander Maringer) for providing beetles and spruce logs. Finally, thank you to two anonymous reviewers and the subject editor (Andrea Battisti) for constructive comments on earlier versions of the manuscript.

Funding Open access funding provided by University of Natural Resources and Life Sciences Vienna (BOKU). Open access funding provided by Austrian Science Fund (FWF). Austrian Science Fund, FWF (P26749-B25 to C.S.), 120 Jahre Universität für Bodenkultur (to M.S), Hochschuljubiläumsfonds der Stadt Wien (H-289980/2016 to M.S.)

Data availability All data are provided in the electronic supplementary material (File: Supplementary Information 4).

\section{Declarations}

Conflicts of interest The authors declare no conflict of interest.

Open Access This article is licensed under a Creative Commons Attribution 4.0 International License, which permits use, sharing, adaptation, distribution and reproduction in any medium or format, as long as you give appropriate credit to the original author(s) and the source, provide a link to the Creative Commons licence, and indicate if changes were made. The images or other third party material in this article are included in the article's Creative Commons licence, unless indicated otherwise in a credit line to the material. If material is not included in the article's Creative Commons licence and your intended use is not permitted by statutory regulation or exceeds the permitted use, you will need to obtain permission directly from the copyright holder. To view a copy of this licence, visit http://creativecommons.org/licenses/by/4.0/.

\section{References}

Anderbrant O (1990) Gallery construction and oviposition of the bark beetle Ips typographus (Coleoptera: Scolytidae) at different breeding densities. Ecolo Entomol 15:1-8. https://doi.org/10.1111/j. 1365-2311.1990.tb00777.x

Anderbrant O, Löfqvist J (1988) Relation between first and second brood production in the bark beetle Ips typographus (Scolytidae). Oikos 53:357-365. https://doi.org/10.2307/3565536

Annila E (1969) Influence of temperature upon the development and voltinism of Ips typographus L. (Coleoptera, Scolytidae). Annales Zoologici Fennici 6:161-208

Arnold JB et al (2021) ggthemes: extra themes, scales and geoms for 'ggplot2'.

Baier P, Pennerstorfer J, Schopf A (2007) PHENIPS - a comprehensive phenology model of Ips typographus (L.) (Col., Scolytinae) as a tool for hazard rating of bark beetle infestation. Forest Ecol Manag 249:171-186. https://doi.org/10.1016/j.foreco.2007.05.020

Bradshaw WE, Quebodeaux MC, Holzapfel CM (2003) Circadian rhythmicity and photoperiodism in the pitcher-plant mosquito: 
adaptive response to the photic environment or correlated response to the seasonal environment? Am Nat 161:735-748. https://doi.org/10.1086/374344

Danks H (1987) Insect dormancy: an ecological perspecitve. Biological Survey of Canada, Ottawa, Canada

Denlinger DL (2002) Regulation of diapause. Annual Rev Entomol 47:93-122. https://doi.org/10.1146/annurev.ento.47.091201. 145137

Dolezal P, Sehnal F (2007) Effects of photoperiod and temperature on the development and diapause of the bark beetle Ips typographus. J Appl Entomol 131:165-173. https://doi.org/10.1111/j. 1439-0418.2006.01123.x

Dworschak K (2013) Ecophysiology of the European spruce bark beetle (Ips typographus L.): factors affecting individual fitness, dispersal and population dynamics. PhD Thesis, TU Munich

Fox J, Weisberg S (2019) An R companion to applied regression, 3rd edn. Sage, Thousand Oaks, CA

Hahn DA, Denlinger DL (2011) Energetics of insect diapause. Annual Rev Entomol 56:103-121. https://doi.org/10.1146/annur ev-ento-112408-085436

Horntvedt R, Christiansen C, Solheim H, Wang S (1983) Artificial inoculation with Ips typographus-associated blue-stain fungi can kill healthy Norway spruce trees. Meddelelser fra Norsk Institutt for Skogforskning 38:1-20

Hulcr J, Atkinson TH, Cognato AI, Jordal BH, McKenna DD (2015) Morphology, taxonomy, and phylogenetics of bark beetles. In: Vega FE, Hofstetter RW (eds) Bark beetles: biology and ecology of native and invasive species. Academic Press, New York, USA, pp 41-84. https://doi.org/10.1016/B978-0-12-417156-5.00002-2

Jakoby O, Lischke H, Wermelinger B (2019) Climate change alters elevational phenology patterns of the European spruce bark beetle (Ips typographus). Global Change Biol 25:4048-4063. https://doi.org/ 10.1111/gcb.14766

Jönsson AM, Appelberg G, Harding S, Barring L (2009) Spatio-temporal impact of climate change on the activity and voltinism of the spruce bark beetle Ips typographus. Global Change Biol 15:486-499. https://doi.org/10.1111/j.1365-2486.2008.01742.x

Kausrud K, Okland B, Skarpaas O, Gregoire JC, Erbilgin N, Stenseth NC (2012) Population dynamics in changing environments: the case of an eruptive forest pest species. Biol Rev 87:34-51. https://doi.org/ 10.1111/j.1469-185X.2011.00183.x

Kirkendall LR, Biedermann PHW, Jordal BH (2015) Evolution and diversity of bark and ambrosia beetles. In: Vega FE, Hofstetter RW (eds) Bark beetles: biology and ecology of native and invasive species. Academic Press, New York, USA, pp 85-156. https://doi.org/10. 1016/B978-0-12-417156-5.00003-4

Kostal V (2006) Eco-physiological phases of insect diapause. J Insect Physiol 52:113-127. https://doi.org/10.1016/j.jinsphys.2005.09.008

Kostal V, Dolezal P, Rozsypal J, Moravcova M, Zahradnickova H, Simek P (2011) Physiological and biochemical analysis of overwintering and cold tolerance in two Central European populations of the spruce bark beetle Ips typographus. J Insect Physiol 57:1136-1146. https://doi.org/10.1016/j.jinsphys.2011.03.011

Kostal V, Zahradnikova H, Simek P, Zeleny J (2007) Multiple component system of sugars and polyols in the overwintering spruce bark beetle Ips typographus. J Insect Physiol 53:580-586. https://doi.org/10. 1016/j.jinphys.2007.02.009

Lieutier F, Yart A, Salle A (2009) Stimulation of tree defenses by Ophiostomatoid fungi can explain attack success of bark beetles on conifers. Ann For Sci 66:801. https://doi.org/10.1051/forest/2009066

Marini L et al (2017) Climate drivers of bark beetle outbreak dynamics in Norway spruce forests. Ecography 40:1426-1435. https://doi.org/ 10.1111/ecog.02769

Merker E, Wild M (1954) Das Reifen der Geschlechtsdrüsen bei dem großen Fichtenborkenkäfer und sein Einfluß auf das Verhalten der Tiere. Contributions to Entomology 4:451-468
Netherer S (2003) Modelling of bark beetle development and of site- and stand-related predisposition to Ips typographus (L.) (Coleoptera; Scolytidae). A contribution to risk assessment. PhD Thesis, BOKU Vienna

Paolucci S, van de Zande L, Beukeboom LW (2013) Adaptive latitudinal cline of photoperiodic diapause induction in the parasitoid Nasonia vitripennis in Europe. J Evolution Biol 26:705-718. https://doi.org/ 10.1111/jeb.12113

Peters G (2018) userfriendlyscience: quantitative analysis made accessible, $0.7 .2 \mathrm{edn}$.

Raffa KF, Grégoire J-C, Lindgren BS (2015) Natural history and ecology of bark beetles. In: Vega FE, Hofstetter RW (eds) Bark beetles: biology and ecology of native and invasive species. Academic Press, New York, USA, pp 1-40. https://doi.org/10.1016/B978-012-417156-5.00001-0

RCoreTeam (2020) R: A language and environment for statistical computing. R Foundation for Statistical Computing, Vienna, Austria

Schebeck M, Hansen EM, Schopf A, Ragland GJ, Stauffer C, Bentz BJ (2017) Diapause and overwintering of two spruce bark beetle species. Physiol Entomol 42:200-210. https://doi.org/10.1111/phen. 12200

Schelhaas MJ, Nabuurs GJ, Schuck A (2003) Natural disturbances in the European forests in the 19th and 20th centuries. Global Change Biol 9:1620-1633. https://doi.org/10.1046/j.1365-2486.2003.00684.x

Schlyter F, Birgersson G, Byers JA, Löfqvist J, Bergström G (1987) Field response of spruce bark beetle, Ips typographus, to aggregation pheromone candidates. J Chem Ecol 13:701-716. https://doi.org/ 10.1007/Bf01020153

Schlyter F, Byers JA, Löfqvist J (1987) Attraction to pheromone sources of different quantity, quality, and spacing: density-regulation mechanisms in bark beetle Ips typographus. J Chem Ecol 13(6):1503-1523

Schopf A (1985) Zum Einfluß der Photoperiode auf die Entwicklung und Kälteresistenz des Buchdruckers, Ips typographus L. (Col., Scolytidae). J Pest Sci 58:73-75. https://doi.org/10.1007/Bf01903228

Schopf A (1989) Die Wirkung der Photoperiode auf die Induktion der Imaginaldiapause von Ips typographus (L.) (Col., Scolytidae). J Appl Entomol 107:275-88. https://doi.org/10.1111/j.1439-0418. 1989.tb00257.x

Schroeder M, Dalin P (2017) Differences in photoperiod-induced diapause plasticity among different populations of the bark beetle Ips typographus and its predator Thanasimus formicarius. Agr For Entomol 19:146-153. https://doi.org/10.1111/afe.12189

Seidl R, Muller J, Hothorn T, Bassler C, Heurich M, Kautz M (2016) Small beetle, large-scale drivers: how regional and landscape factors affect outbreaks of the European spruce bark beetle. J Appl Ecol 53:530-540. https://doi.org/10.1111/1365-2664.12540

Stadelmann G, Bugmann H, Wermelinger B, Bigler C (2014) Spatial interactions between storm damage and subsequent infestations by the European spruce bark beetle. Forest Ecol Manag 318:167-174. https://doi.org/10.1016/j.foreco.2014.01.022

Stefkova K, Okrouhlik J, Dolezal P (2017) Development and survival of the spruce bark beetle, Ips typographus (Coleoptera: Curculionidae: Scolytinae) at low temperatures in the laboratory and the field. Eur J Entomol 114:1-6. https://doi.org/10.14411/eje.2017.001

Tauber MJ, Tauber CA (1972) Geographic variation in critical photoperiod and in diapause intensity of Chrysopa carnea (Neuroptera). J Insect Physiol 18:25-29. https://doi.org/10.1016/0022-1910(72) 90061-3

Tauber MJ, Tauber CA (1976) Insect seasonality: diapause maintenance, termination, and postdiapause development. Annual Rev Entomol 21:81-107. https://doi.org/10.1146/annurev.en.21.010176.000501

Tauber MJ, Tauber CA, Masaki S (1986) Seasonal adaptations of insects. Oxford University Press, Oxford, U.K.

Visser ME, Caro SP, van Oers K, Schaper SV, Helm B (2010) Phenology, seasonal timing and circannual rhythms: towards a unified 
framework. Philos T R Soc B 365:3113-3127. https://doi.org/10. 1098/rstb.2010.0111

Wermelinger B (2004) Ecology and management of the spruce bark beetle Ips typographus - a review of recent research. Forest Ecol Manag 202:67-82. https://doi.org/10.1016/j.foreco.2004.07.018

Wermelinger B, Epper C, Kenis M, Ghosh S, Holdenrieder O (2012) Emergence patterns of univoltine and bivoltine Ips typographus (L.) populations and associated natural enemies. J Appl Entomol 136:212-224. https://doi.org/10.1111/j.1439-0418.2011.01629.x

Wermelinger B, Seifert M (1998) Analysis of the temperature dependent development of the spruce bark beetle Ips typographus $(\mathrm{L})(\mathrm{Col}$, Scolytidae). J Appl Entomol 122:185-191. https://doi.org/10.1111/j. 1439-0418.1998.tb01482.x

Wermelinger B, Seifert M (1999) Temperature-dependent reproduction of the spruce bark beetle Ips typographus, and analysis of the potential population growth. Ecol Entomol 24:103-110. https://doi.org/10. 1046/j.1365-2311.1999.00175.x

Wickham H (2016) ggplot2: elegant graphics for data analysis. Springer, New York

Winterhalter WE, Mousseau TA (2007) Patterns of phenotypic and genetic variation for the plasticity of diapause incidence. Evolution 61:1520-1531. https://doi.org/10.1111/j.1558-5646.2007.00127.x

Publisher's Note Springer Nature remains neutral with regard to jurisdictional claims in published maps and institutional affiliations. 